\title{
Genetic evidence for a chromosomally integrated multiresistance plasmid in Salmonella dublin
}

\author{
M. J. WOODWARD, I. MCLAREN and C. WRAY
}

Department of Bacteriology, MAFF Central Veterinary Laboratory, New Haw, Weybridge, Surrey KT15 3NB

\begin{abstract}
Summary. Of 1099 isolates of Salmonella dublin during 1985-86, $11(1 \%)$ were resistant to three or more antibiotics. Strain S4659/85, a multiresistant isolate, lacked autonomous $\mathrm{R}$ plasmids but showed incompatibility with inc $\mathrm{H} 2$ plasmids and donated resistance determinants in matings. Transconjugants acquired incomplete $\mathrm{R}$ plasmids which integrated stably into a specific chromosomal site. These data provide an insight into the behaviour of $\mathrm{R}$ plasmids in $\mathrm{S}$. dublin.
\end{abstract}

\section{Introduction}

During the period 1985-86, Salmonella dublin was the second most common serotype isolated from cattle in Great Britain (Anon, 1985; Wray, 1985 and unpublished data). Although antibiotic multiresistance is uncommon in $S$. dublin, most bovine isolates of $S$. typhimurium and $70 \%$ of continental isolates of $S$. dublin are multiresistant (Helmuth and Seiler, 1986; Jorgensen, 1986; Sojka et al., 1986). Since British isolates are subjected to the same antibiotic selective pressures as the multiresistant strains of Salmonella, it is possible that they are refractory to plasmids common to the enteric bacterial pool.

This paper reports a survey of antibiotic sensitivities of $S$. dublin isolates and presents evidence for chromosomal integration of a multiresistant conjugative inc $\mathrm{H} 2$ plasmid in one isolate.

\section{Materials and methods}

\section{Strains and plasmids}

Escherichia coli $\mathrm{K} 12$ marker strains were $\mathrm{J} 62.1 \mathrm{~F}^{-}$lac pro his trp nalA, $\mathrm{C} 600 \mathrm{~F}^{-}$lac thr leu thi supE tonA, RG192 $\mathrm{F}^{-}$lac ara-leu thi rif (National Collection of Type Cultures, Colindale, London), UB5201 $\mathrm{F}^{-}$pro met nalA $\operatorname{rec} A$ (P. Bennett, Bristol University), AB2575 Hfr ilv tsx thiA, $\mathrm{R} 4 \mathrm{Hfr}$ relA1 metBI, and $\mathrm{AB} 1621 \mathrm{~F}^{-}$ara gal tsx rpsl xylmtl glpD thiA (H. P. Charles, Reading University). Genotypic symbols follow Bachmann and Low (1980). Plasmids used were pWR23 incIH2 Suc Lac Tc, pMIP233 incIH3 Suc Tc, pFoLac incFV/OF Lac, pR821 a incI2 Pn, pRP4 inc P Pn Km Tc, and pR6K incX Pn, Sm, harboured in E. coli $\mathrm{K} 12$ strains RG192, RG192, C600, J53.1,

Received 17 Feb. 1988; revised version accepted 23 Aug. 1988.
HB 101 and J53 respectively (Plasmid Reference Centre, Colindale). Plasmid nomenclature follows Novick et al. (1976).

\section{Media and antibiotics}

Complete medium (Alaeddinoglu and Charles, 1979) was used for maintenance and culture of all bacterial strains. Minimal medium (Vogel and Bonner, 1956) supplemented with glucose or other sugars $0 \cdot 2 \% \mathrm{w} / \mathrm{v}$ was used for all selections in genetic crosses. Growth requirements were added to a final concentration of $40 \mu \mathrm{g} / \mathrm{ml}$. Antibiotics (Sigma) were added to complete and minimal media at a final concentration of $40 \mu \mathrm{g} / \mathrm{ml}$ unless otherwise stated.

\section{Sensitivity tests}

A diffusion method with the multodisk technique (Sojka et al., 1986) was used.

\section{Genetic methods}

Conjugative plasmid and chromosomal time-of-entry transfer was by filter and broth matings, respectively (Willetts, 1984). Transduction with bacteriophage $\mathrm{Pl}$ was as described by Glansdorff (1965).

\section{Plasmid isolation}

Extraction methods of Birnboim and Doly (1979), Kado and Liu (1981) and Holmes and Quigley (1981), as described by Maniatis et al. (1982), were used. Agarose gel electrophoresis and visualisation of plasmid bands in agarose gels was as described by Maniatis et al. (1982). Plasmid sizes were estimated by comparing migration distances against reference plasmids of $142,60 \cdot 9,34.6$ and $6.1 \mathrm{~kb}$ extracted from strain 39R861 (Plasmid Reference Centre, Colindale). 


\section{Results}

\section{Antibiotic-resistance patterns in S. dublin}

During 1985-86, $1099 \mathrm{~S}$. dublin isolates (1047 from cattle, 32 from sheep, nine from other species, eight from feed and three from the environment) were screened for sensitivity to antibiotics (table I). Sensitivity to all antibiotics tested was shown by $22 \%$ of isolates; $44 \%$ were resistant to streptomycin, $12 \%$ to sulphonamides and $20 \%$ to both streptomycin and sulphonamides; 11 isolates $(1 \%)$ were resistant to three or more antibiotics, and were designated multiresistant. This low percentage of multiresistance in $S$. dublin for the years 1985-86 reflects a continuing trend in Great Britain (Sojka and Hudson, 1976; Threlfall et al., 1979; Sojka et al., 1986).

Cell lysates of eight multiresistant $S$. dublin isolates were subjected to agarose-gel electrophoresis, to analyse plasmid content (fig. 1a, lanes A-E; fig. 1b, lanes A-E; fig. 2, lanes $F$ and $H$ ). All harboured the $72 \cdot 5-\mathrm{kb}$ putative virulence plasmid (Terakado et al., 1983; Chikama et al., 1985; Helmuth et al., 1985; Manning et al., 1986). With one exception, all multiresistant isolates harboured at least one other plasmid. Isolate $\mathbf{S 4 6 5 9 / 8 5 \text { , }}$ resistant to tetracycline, chloramphenicol, neomycin, sulphonamide, trimethoprim and streptomycin, harboured the $72 \cdot 5-\mathrm{kb}$ plasmid only (fig. $1 \mathrm{~b}$, lanes A, C, E) suggesting that resistance determinants were chromosomally integrated.

\section{Resistance plasmid harboured by strain S4659/85}

Mating experiments were set up to test whether promiscuous plasmids encoding antibiotic multires- istance (Hardy, 1986) were transferable from strain $\mathrm{S} 4659 / 85$ to $E$. coli $\mathrm{K} 12$ recipient strains. In these tests selection was made for tetracycline, neomycin and chloramphenicol separately (table II). Significantly, transfer of resistance determinants was detected only after mating periods of $16 \mathrm{~h}$ or more and at a mating temperature of $30^{\circ} \mathrm{C}$. Shorter mating periods or increased mating temperatures gave no growth on selection plates.

Dependence upon cell-to-cell contact for transfer of resistance determinants was tested by mixing cell-free supernates of strain S4659/85 before and after DNAase treatment with late log-phase cultures of $E$. coli $\mathrm{K} 12$ recipients. No recombinants were detected after mixtures which had been incubated for $16 \mathrm{~h}$ at $30^{\circ} \mathrm{C}$ were plated on selection media, suggesting that transfer was not the result of transduction by bacteriophage nor transformation by free DNA.

The frequency of transfer for each resistance determinant to $E$. coli recipient J62.1 was low (table II). Transconjugants selected for resistance to tetracycline were obtained at a frequency 100 -fold lower than when selection was for chloramphenicol or neomycin resistances. It was possible that the concentration of tetracycline was close to the MIC, thus causing inhibition of growth of transconjugants. Transconjugants were tested for acquisition of the non-selected resistance determinants by replica plating (table II). Co-transfer was not always $100 \%$, suggesting either F-like chromosomal transfer or plasmid breakdown.

To test for F-like transfer, mating experiments were made with a recombination-deficient mutant, UB5201 rec $A$, as recipient. Transfer and co-transfer frequencies (table II) were similar to mating with

Table I. Antibiotic resistance patterns of S. dublin isolates in 1985-86

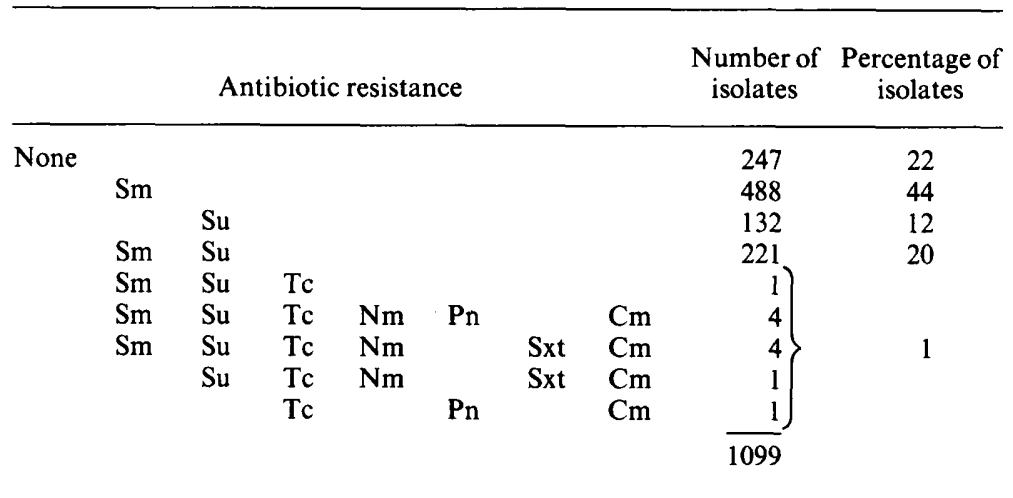

Antibiotics were: streptomycin (Sm) $10 \mu \mathrm{g}$ disk, compound sulphonamide (Su) $50 \mu \mathrm{g}$, tetracycline (Tc) $10 \mu \mathrm{g}$, neomycin (Nm) $10 \mu \mathrm{g}$, ampicillin (Pn) $10 \mu \mathrm{g}$, sulphamethoxaxole/trimethoprim (Sxt) $25 \mu \mathrm{g}$, chloramphenicol $(\mathrm{Cm}) 10 \mu \mathrm{g}$. 


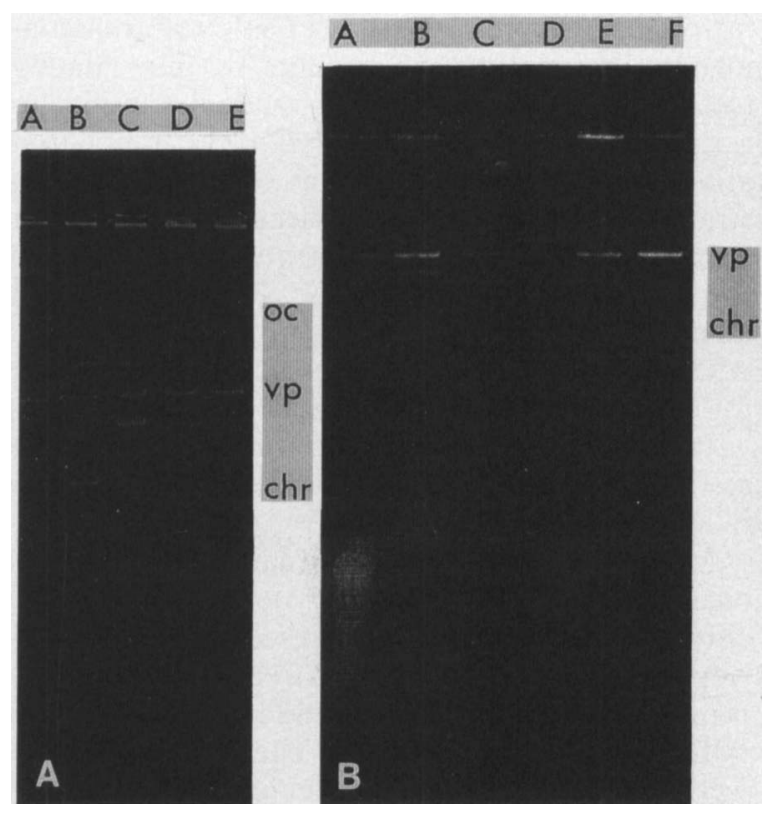

Fig. 1a. Cell lysates of five multiresistant $S$. dublin isolates run through $0.7 \%$ argarose and visualised by UV transillumination after ethidium bromide staining: S4909/85 Sm Su Tc Nm Pn Cm (lane A); S4809/85 Su Tc Nm Sxt Cm (lane B); S5135/85 Sm Su Tc Nm Pn Sxt Cm (lane C); S1445/85 Sm Su Tc Nm Sxt Cm (lane D); and S 4659/85 Sm Su Tc Nm Sxt Cm (lane E). Extraction was by the method of Birnboim and Doly (1979). Residual chromosomal DNA (chr) and the putative $S$. dublin virulence plasmid of $72 \cdot 5-\mathrm{kb}(\mathrm{vp})$ and its open circular form (oc) are indicated.

Fig. 1b. Cell lysates of multiresistant $S$. dublin isolates run through $0.7 \%$ agarose and visualised by UV transillumination after ethidium bromide staining: S4659/85 Sm Su Tc Nm Sxt Cm extracted by the methods of Kado and Liu (1981) (lane A), Birnboim and Doly (1979) (lane C), and Homles and Quigley (1981) as described by Maniatis et al. (1982) (lane E); S3717/85 Tc Pn Cm (lane B), S5260/85 Sm Su Tc Nm Sxt Cm (lane D) and sensitive strain $S 1447 / 85$ (lane F) were extracted by the method of Birnboim and Doly (1979). Residual chromosomal DNA (chr) and the putative $S$. dublin $72 \cdot 5-\mathrm{kb}$ virulence plasmid (vp) are indicated.

recombination-proficient recipient $\mathrm{J} 62.1$. Independence from the recipient's recombination system indicated transfer by autonomous plasmid.

\section{Physical evidence for plasmids in transconjugants}

Repeated attempts to demonstrate a plasmid, other than the $72.5-\mathrm{kb}$ plasmid, in strain $\mathrm{S} 4659 / 85$ failed and yet the evidence presented above indicated the involvement of a plasmid in determining resistance and its transfer. Transconjugant J62.1 and UB5201 rec $A$ colonies picked at random directly from selection plates were analysed for plasmid content. Plasmids corresponding to about 87-94 kb were detected. Fig. 2 (lanes A-E) shows

\section{A BCDEF G H I J K L M}

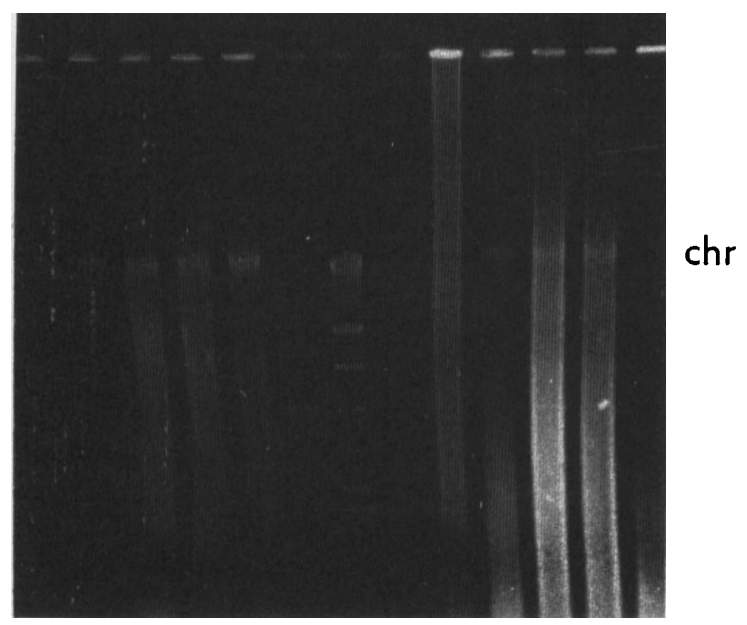

Fig. 2. Cell lysates from five different UB5201recA transconjugants picked directly from tetracycline selection plates, after matings with strain $\mathrm{S} 4659 / 85$ as donor, were extracted by the method of Kado and Liu (1981) (lanes A-E). The same five UB5201 recA transconjugants were also subcultured by streaking on selection plates containing tetracycline, and single colonies were extracted by the method of Kado and Liu (1981) (lanes IM). Strains S5260/85 Sm Su Tc Nm Pn Cm (lane F) and S4659/ 85 (lane $\mathrm{H}$ ) were extracted by the method if Kado and Liu (1981). Linear molecular weight markers, lambda Hind III digested DNA (lane G) were also run. Agarose concentration was $0.7 \%$, and DNA species were visualised by UV transillumination after ethidium bromide staining. Residual chromosomal DNA (chr) is indicated.

the profiles of five UB5201recA transconjugants picked from selection plates containing tetracycline. Similar faint plasmid bands were demonstrated in both J62.1 and UB5201recA transconjugants picked from selection plates separately containing chloramphenicol and neomycin. Small differences in plasmid size were observed, but whether size variation was caused by deletion or was an artefact of the gels was unclear. Subcultured J62.1 and UB5201recA transconjugants did not harbour autonomous plasmids, suggesting either plasmid intregration into the chromosome or plasmid suicide. Fig. 2 (lanes I-M) shows the profiles of the same five UB5201recA transconjugants exemplified in fig. 2 (lanes A-E) but after one subculturing on complete medium containing tetracycline.

\section{Stable chromosomal integration of resistance determinants}

If the plasmid was not surviving soon after transfer, loss of antibiotic resistance might be 
Table II. Transfer of resistance determinants in mating experiments between $S$. dublin strain $\$ 4659 / 85$ and $E$. coli $\mathrm{K} 12$ recipient strains

\begin{tabular}{lccccc} 
& & & \multicolumn{3}{c}{$\begin{array}{c}\text { Percentage co-transfer } \\
\text { of non-selected resist- } \\
\text { ance determinant }\end{array}$} \\
\cline { 4 - 7 } $\begin{array}{l}\text { Recipient } \\
\text { strain of } \\
\text { E. coli K12 }\end{array}$ & $\begin{array}{c}\text { Marker } \\
\text { selected }\end{array}$ & $\begin{array}{c}\text { Frequency of } \\
\text { transfer/donor }\end{array}$ & $\mathrm{Cm}$ & $\mathrm{Nm}$ & $\mathrm{Tc}$ \\
\hline $\mathrm{J} 62.1$ & $\mathrm{Cm}$ & $2 \times 10^{-4}$ & $\ldots$ & 100 & 80 \\
& $\mathrm{Nm}$ & $2 \times 10^{-4}$ & 100 & $\ldots$ & 80 \\
& $\mathrm{Tc}$ & $3 \times 10^{-6}$ & 74 & 74 & $\ldots$ \\
UB5201recA & $\mathrm{Cm}$ & $3 \times 10^{-4}$ & $\ldots$ & 100 & 94 \\
& $\mathrm{Nm}$ & $4 \times 10^{-4}$ & 100 & $\ldots$ & 96 \\
& $\mathrm{Tc}$ & $7 \times 10^{-5}$ & 85 & 87 & $\ldots$ \\
\hline
\end{tabular}

See footnote to table I; and see text for conditions of mating.

anticipated. To test this, about 20 transconjugant colonies picked from selection plates were tested for resistance patterns and then grown for about 50 generations in non-selective conditions. No differences in resistance pattern were detected, indicating very stable inheritance of resistance determinants.

An alternative explanation for loss of autonomous plasmid in transconjugants with stable inheritance of resistance determinants was that resistance determinants were encoded within transposable genetic elements. Upon suicide of the plasmid, survival of resistance determinants would require their transposition on to the chromosome. If this were so, transconjugants would not act as donors of resistance determinants in mating experiments, unless a helper plasmid was introduced to act as target and vector for transposable genetic elements. Plasmids pR821a, pRP4 and pR6K were introduced into four $\mathrm{J} 62.1 \mathrm{Tc}^{r} \mathrm{Cm}^{\mathrm{r}} \mathrm{Nm}^{r}$ transconjugants in separate experiments by filter mating (see Methods), selection being made for ampicillin resistance in each case. Ampicillin-resistant derivatives were then filter mated at $30^{\circ} \mathrm{C}$ for $16 \mathrm{~h}$ with strain AB1621 as recipient. Selection was made for ampicillin alone, to demonstrate helper plasmid transfer to strain AB1621, and for resistances not determined by the helper plasmid. For example, with pRP4 Pn Km Tc as helper, selection was made for chloramphenicol resistance. Transconjugants with and without helper plasmid did not donate resistance determinants at a detectable frequency in any mating experiment.

Mapping experiments were performed to demonstrate that the resistance determinants were chromosomally located in transconjugants. Bacteriophage Pl lysates were prepared from four J62.1 transconjugants chosen at random from different initial mating experiments. The transconjugants were resistant to tetracycline, chloramphenicol and neomycin (sulphonamide, trimethoprim and streptomycin were not tested). Lysates were used to transduce Hfr AB2575ilv and Hfr R4met to prototrophy and resistance. Frequencies of transduction (table III) were satisfactory. Co-transduction frequencies between resistance determinants showed that chloramphenicol and neomycin resistance determinants on the one hand, and the tetracycline resistance determinant on the other, were closely linked but separated by an intervening sequence homologous with the $E$. coli $\mathrm{K} 12$ chromosome permitting recombination.

Transductants of $\mathrm{Hfr} \mathrm{R} 4$ and $\mathrm{Hfr}$ AB2575, resistant to the three antibiotics tested, were used as donors in time-of-entry conjugation experiments

Table III. Transduction of resistance determinants from transconjugants to E. coli K12 Hfr strains

\begin{tabular}{|c|c|c|c|c|c|}
\hline \multirow[b]{2}{*}{ Recipient } & \multirow{2}{*}{$\begin{array}{l}\text { Marker } \\
\text { selected }\end{array}$} & \multirow{2}{*}{$\begin{array}{l}\text { Frequency of } \\
\text { transduction/donor } \\
\text { phage }\end{array}$} & \multicolumn{3}{|c|}{$\begin{array}{l}\text { Percentage co-transduction of } \\
\text { non-selected resistance } \\
\text { determinants }\end{array}$} \\
\hline & & & $\mathrm{Cm}$ & $\mathrm{Nm}$ & $\mathrm{Tc}$ \\
\hline \multirow[t]{4}{*}{ Hfr AB2575ilv } & $i l v^{+}$ & $2.0 \times 10^{-5}$ & 0 & 0 & 0 \\
\hline & $\mathrm{Cm}$ & $1.1 \times 10^{-6}$ & & 100 & 68 \\
\hline & $\mathrm{Nm}$ & $1.9 \times 10^{-6}$ & 100 & & 66 \\
\hline & $\mathrm{Tc}$ & $1.7 \times 10^{-6}$ & 73 & 73 & $\ldots$ \\
\hline \multirow[t]{4}{*}{ Hfr R4met } & $\mathrm{met}^{+}$ & $1.3 \times 10^{-5}$ & 0 & 0 & 0 \\
\hline & $\mathrm{Cm}$ & $2 \cdot 3 \times 10^{-6}$ & $\ldots$ & 100 & 72 \\
\hline & $\mathrm{Nm}$ & $1.7 \times 10^{-6}$ & 100 & $\ldots$ & 71 \\
\hline & $\mathrm{Tc}$ & $8.7 \times 10^{-6}$ & 69 & 69 & $\ldots$ \\
\hline
\end{tabular}

See footnote to table I. 
with $E$. coli $\mathrm{K} 12 \mathrm{AB} 1621$ as recipient. Hfr AB2575 donates its chromosome in an anticlockwise direction with a point of origin at minute 95 on the $E$. coli $\mathrm{K} 12$ linkage map. Hfr R4 donates clockwise from minute 5 . The earliest time of entry of resistance determinants was $25 \mathrm{~min}$ with strain AB2575 and 85 min with strain R4, locating the resistance determinants at minute 20 of the $E$. coli K12 linkage map.

\section{Chromosomally integrated plasmid of strain S4659/ 85 belonging to the inc $\mathrm{H} 2$ incompatibility group}

Plasmids of incompatibility group inc $\mathrm{H} 2$ are conjugally transmissible at $30^{\circ} \mathrm{C}$ or below (Johnson et al., 1976), a feature in common with the chromosomally integrated plasmid in strain S4659/ 85. In reciprocal matings between strains $S 4659 / 85$ and RG192 pWR23 (incH2), only rare microcolonies were detected on plates selecting for retention of both plasmids in one or other strain. Propagation of microcolonies by subculture on joint selection plates failed. In control experiments, to verify that strain $\mathrm{S} 4659 / 85$ could act as recipient as well as donor in such matings, plasmids pMIP233 (incH3) and pFolac (incFV) were shown to be compatible. That strain $\mathrm{S} 4659 / 85$ stably maintained inc $\mathrm{H} 3$ and inc $\mathrm{FV}$ but not inc $\mathrm{H} 2$ plasmids suggests that an inc $\mathrm{H} 2$ plasmid was resident in the chromosome.

\section{Discussion}

The reason for the rarity of multiresistant $S$. dublin strains in Great Britain is a matter for speculation. It is possible that maintenance of plasmids, other than the $72 \cdot 5-\mathrm{kb}$ putative virulence plasmid, is selectively disadvantageous during the onset of infection. It seems unlikely that $S$. dublin is an inhospitable host to plasmids since plasmidbearing strains were demonstrated and plasmids were readily introduced. Indeed, sensitive $S$. dublin strains have been shown to receive and maintain $\mathbf{R}$ plasmids representative of 15 incompatibility groups (unpublished data). Multiresistance plasmid absence from $S$. dublin remains intriguing.

Strain S4659/85 was unique in that it harboured a conjugally transmissible inc $\mathrm{H} 2$ plasmid in its chromosome. The extended mating period required for successful transfer and the possible size variation of plasmids in transconjugants suggested that the plasmid in strain $\mathrm{S} 4659 / 85$ excised from the chromosome infrequently and possibly illegitimately. If the size variation of newly acquired plasmids in transconjugants was genuine and not an artefact of the gels, their inability to act as donors indicates loss of essential transfer functions. Whether that loss was caused by imprecise excision from the donor chromosome or as a result of recombination events upon entering $E$. coli is unknown.

Integration of the plasmid into the $E$. coli $\mathrm{K} 12$ chromosome of $U B 5201 \mathrm{rec} A$ strongly suggests regions of homology between plasmid and chromosome and that the plasmid may encode its own recombination system, perhaps in the form of insertion sequences or transposons (Calos and Miller, 1980). Whether the chromosomal location of plasmid insertion in E. coli $\mathrm{K} 12$ is the same as that in $S$. dublin is unknown. Homology between plasmid and chromosome was confirmed by transductions in which crossovers between chromosome and intervening sequences within the antibiotic resistance encoding region were demonstrated.

If plasmids confer disadvantage upon $S$. dublin, by draining energy and metabolites from the central pool to support replication, for example, there exists a selective pressure upon plasmids to reduce that burden. Whether integration of plasmids into the chromosome alleviates that burden is debatable.

Helmuth and Seiler (1986) demonstrated in Southern hybridisations that a 700-bp internal DNA fragment, from the chloramphenicol acetyl transferase gene of $\mathrm{pBR} 325$, hybridised with chromosomal DNA from a plasmid-free multiresistant isolate of $S$. dublin. Although transfer of resistance determinants was not detected, and incompatibility and transposon tests were not done, it is possible that strain $\mathrm{S} 4659 / 85$ is the same as, or similar to, those isolates described by Helmuth and Seiler (1986). Furthermore, they went on to report a dramatic increase, from $16 \%$ to $70 \%$, in this $\mathrm{R}$ plasmid-free type of $S$. dublin isolate in the Federal Republic of Germany in the mid-1970s.

Stability and conjugal transmissibility of the resistance phenotype of $S$. dublin $\mathrm{S} 4659 / 85$ is a cause for concern. If this isolate represents a virulent clone currently in circulation in Great Britain, we might see a dramatic increase in the isolation of multiresistant $S$. dublin from animal infections. 


\section{REFERENCES}

Anon 1985 Animal salmonellosis. 1984 Annual summaries. Ministry of Agriculture, Fisheries and Food. Welsh Office Agriculture Department. Department of Agriculture and Fisheries for Scotland.

Alaeddinoglu N G, Charles H P 1979 Transfer of a gene for sucrose utilization in Escherichia coli $\mathrm{K} 12$ and consequent failure of expression of genes for D-serine utilization. Journal of General Microbiology 110 : 47-59.

Bachmann B J, Low K B 1980 Linkage map of Escherichia coli K12. Microbiological Reviews 44: 1-56.

Birnboim H C, Doly J 1979 A rapid alkaline extraction procedure for screening recombinant plasmid DNA. Nucleic Acids Research 7: 1515-1523.

Calos M P, Miller J H 1980 Transposable elements. Cell 20: 579-595.

Chikama G K, Fierer J, Guiney D G 1985 Plasmid mediated virulence in Salmonella dublin demonstrated by use of a Tn5-oriT construct. Infection and Immunity 50: 420-424.

Glansdorff N 1965 Topography of cotransducible arginine mutations in Escherichia coli K12. Genetics 51 : 167-169.

Hardy K 1986 Bacterial plasmids, 2nd edn. Van Nostrand Reinhold, Wokingham, England.

Helmuth R, Stephan R, Bunge C, Hoog B, Steinbeck A, Bulling E 1985 Epidemiology of virulence-associated plasmids and outer membrane protein patterns within seven common Salmonella serotypes. Infection and Immunity 48: 175-182.

Helmuth R, Sailer A 1986 Epidemiology and chromosomal location of genes encoding multiresistance in Salmonella dublin. Journal of Antimicrobial Chemotherapy 18 Suppl C: 179-181.

Holmes D S, Quigley M 1981 A rapid boiling method for the preparation of bacterial plasmids. Analytical Biochemistry 114: 193-197.

Johnson E M, Wohlheiter J A, Placek B P, Sleet R B, Baron L S 1976 Plasmid-determined ability of a Salmonella tennessee strain to ferment lactose and sucrose. Journal of Bacteriology 125: $385-386$.
Jorgensen S T 1986 Antibiotic resistance profiles and molecular epidemiology of Salmonella typhimurium and Salmonella dublin, mainly from cattle. Journal of Antimicrobial Chemotherapy 18C: 183-188.

Kado C I, Liu S T 1981 Rapid procedure for detection and isolation of large and small plasmids. Journal of Bacteriology 145: 1365-1373.

Maniatis T, Fritsch E F, Sambrook J 1982 Molecular cloning: a laboratory manual. Cold Spring Harbor Laboratory, Cold Spring Harbor, New York.

Manning E J, Baird G D, Jones P W 1986 The role of plasmid genes in the pathogenicity of Salmonella dublin. Journal of Medical Microbiology 21 : 239-243.

Novick R P, Clowes R C, Cohen S N, Curtiss R, Datta N, Falkow S 1976 Uniform nomenclature for bacterial plasmids: a proposal. Bacteriology Reviews 40: 168-189.

Sojka W J, Hudson E B 1976 A survey of drug resistance in salmonella isolated from animals in England and Wales during 1972. British Veterinary Journal 132: 95-104.

Sojka W J, Wray C, McLaren I 1986 A survey of drug resistance in Salmonella isolated from animals in England and Wales during 1982 and 83. British Veterinary Journal 142: 371380 .

Terakado N, Sekizaki T, Hashimoto K, Naitoh S 1983 Correlation between the presence of a fifty megadalton plasmid in Salmonella dublin and virulence for mice. Infection and Immunity 41 : 443-444.

Threlfall E J, Hall M L M, Rowe B 1979 Plasmid-mediated antimicrobial drug resistance in Salmonella dublin in food animals. Veterinary Record 105: 20-21.

Vogel H J, Bonner D M 1956 A convenient growth medium for Escherichia coli and some other organisms (medium E). Microbial Genetics Bulletin 13: 43-57.

Willetts N 1984 In: Bennett P M, Grinsted J (eds) Methods in microbiology, vol 17, Plasmid technology. Academic Press, London, England.

Wray C 1985 Is salmonellosis still a serious problem in veterinary practice? Veterinary Record 116: 485-489. 